\title{
Palavras-chave: convergências e diferenciações entre a linguagem natural e a terminologia
}

Diego dos Santos Borba

Bibliotecário da Universidade Federal da Fronteira Sul

Regina Helena Van der Laan

Professora Associada do Departamento de Ciências da Informação da UFRGS. Doutora em Letras/UFRGS

Bernadete Ros Chini

Bibliotecária da Universidade Federal da Fronteira Sul

Relato de literatura com o enfoque na terminologia e na linguística, com o objetivo de estabelecer a contribuição de cada área no atual cenário informacional da representação do conhecimento e de sua posterior recuperação. Destaca a importância das palavras-chave como unidades de representação e de recuperação da informação. Salienta a necessidade de se estabelecer a inter-relação entre linguagem natural e terminologia de um domínio, aperfeiçoando a linguagem documentária. Destaca que um sistema de recuperação da informação, no qual seja representada a informação em consonância com a linguagem dos usuários, possibilitará uma recuperação de informação com maior precisão $e$ pertinência.

Palavras-chave: Sistemas de recuperação da informação; Terminologia; Linguagem natural; Linguagem documentária; Palavra-chave.

\section{convergences and differences between natural language and terminology}

The paper is a literature report with focus on terminology and linguistics. The goal is establish the contribution of each area in the current informational scenario of 
knowledge representation and its subsequent retrieval. It stresses the keywords importance as units of information representation and retrieval. It accentuates the need to establish the interrelationship between natural language and terminology of a domian in order to improve the documentary language. It stresses that an information retrieval system in which information is represented according to users' language will allow information retrieval with greater precision and relevance.

Keywords: Information retrieval systems; Terminology; Natural Language; Documentary Language; Keywords.

Recebido em 22.06.2011 Aceito em 02.04.2012

\section{Introdução}

Neste artigo, é discutida a importância das palavras-chave dos artigos científicos, como unidades de recuperação da informação e, consequentemente, de representação. Sendo assim, o que se propõe é a necessidade de se olhar essa questão sob o prisma da Linguística e da Terminologia, tendo como fato consolidado a explosão informacional e a constante fragmentação do conhecimento.

A palavra-chave é caracterizada por ser atribuída pelo autor, empregando unidades lexicais livres, com o objetivo de representar sinteticamente o conteúdo temático do texto. É inegável que o autor tem, sobre o texto, o domínio informacional proporcionado pela atividade de criação. Nesta perspectiva, entende-se que a palavra-chave deveria ser um termo da área de conhecimento sobre a qual o autor trata. Portanto, seria uma unidade tanto de representação como de recuperação da informação. Diante dessas afirmações, o que se pretende discutir é a capacidade de representação documentária do conteúdo textual para recuperação por um leitor, cuja demanda de informação seja compatível com o assunto representado pela palavra-chave.

Com objetivo de oferecer reflexões sobre essa situação, realizou-se uma revisão de literatura que fosse capaz de analisar as palavras-chave, dentro de um contexto terminológico, informacional e linguístico. Essa revisão possibilita perceber a importância das análises das palavraschave, como elemento significativo para a representação e recuperação de informações das diferentes áreas do conhecimento.

\section{Palavras-chave: Léxico geral ou termos?}

A palavra-chave tem a característica de ser livremente atribuída pelo autor de um texto, visando, assim, a representação do conteúdo informacional presente no documento por ele elaborado. A atividade de atribuir palavras-chave, segundo Fujita (2004b), necessita conhecimento 
do assunto do texto, de modo que ninguém melhor que o autor para executar tal tarefa. Mesmo com o domínio informacional que lhe é justamente proclamado e proporcionado devido à atividade de criação, esse, ainda, precisa ter em mente que é através das palavras-chave, por ele atribuídas, que o leitor poderá avaliar, ainda que de forma superficial, se o texto é compatível com sua necessidade de informação.

Portanto, para determinação de palavras-chaves o autor deverá ter uma visão sobre o texto e a organização do seu conteúdo de modo a representá-lo conforme seu assunto principal e, em outro plano, o objetivo de representação do conteúdo documentário, a visão sobre a demanda do leitor previsto (FUJITA, 2004, p. 258b).

O tratamento temático do documento visa estabelecer uma representação de seu conteúdo, com intuito de uma recuperação eficiente da informação por parte do usuário em um ambiente informacional eletrônico, como bases de dados online ou em catálogos manuais, estes sendo compreendidos, efetivamente, como sistemas de informação. Para tal, é preciso que ocorra uma convergência entre a linguagem de quem busca a informação (usuário) e a linguagem usada para o tratamento temático do documento (sistema de informação). O que se busca nada mais é que uma comunicação entre sistema e usuário através de uma linguagem. Sendo assim, o estudo das palavras-chave só pode ser compreendido com o auxílio do estudo da língua.

Orlandi (2007) nos diz que os sinais produzidos pelo homem através da fala e da escrita são denominados signos. Através dessa intensa produção de signos é que o homem se comunica, expressa seus sentimentos, desejos e ideias e, ainda, interage com o meio em que vive. Dessa forma, o uso da palavra como meio de comunicação depende de interações sociais e psicológicas com o meio em que se vive. Os signos da linguagem verbal são tão importantes na humanidade que mereceram uma ciência exclusiva: a Linguística. Orlandi (2007), que afirma, através de Saussure, que a Linguística passa a ter um objeto específico: a língua. Saussure (1988) conceitua a língua como sendo um sistema de signos constituído por unidades organizadas que formam um todo. As definições de Saussure foram muito importantes para o desenvolvimento de estudos específicos da língua, pois, a partir delas, foi possível a determinação da importância da Linguística como ciência. A definição do signo como a associação do significante (imagem acústica) e significado (conceito) é fundamental para o entendimento dos mecanismos de comunicação e sentido da língua. "Ele diz que é fundamental observar que a imagem acústica não se confunde com o som, pois ela é como o conceito, psíquica e não física" (ORLANDI, 2007, p. 23). Quanto à fala, Araújo (2006) afirma que Saussure estabeleceu a fala como parte secundária da linguagem, tornando-a individual, em um estudo psicofísico. Dessa forma, língua e fala são interdependentes, mas inteiramente distintas. Então, depreende- 
se que a língua é essencial para que a fala seja compreendida e, sendo assim, proporcione a comunicação e toda a interação do ser humano com o meio em que vive.

A terminologia de uma determinada área do conhecimento é aprendida conscientemente através da manifestação voluntária de aprendizagem, enquanto as palavras, que fazem parte do léxico geral, têm seu aprendizado de forma subconsciente, através de interações sociais e psicológicas. "A terminologia é uma ferramenta básica dos especialistas que, sem os termos não poderiam expressar ou comunicar seus conhecimentos" (GALVÃO, 2004, p. 248). Porém, a linguagem do especialista pode ser constituída por palavras do léxico geral. Atualmente, as palavras-chave atribuídas pelos autores nos artigos científicos têm, cada vez mais, se afastado do léxico geral, aproximando-se, assim, da terminologia empregada pelos especialistas. Sager ${ }^{1}$ (1980) apud Galvão (2004) considera a linguagem de especialidade dependente da linguagem geral, pois nela se baseia e dela deriva. Essa afirmação torna evidente a convergência entre a linguagem natural e a Terminologia, mas, ainda, não é possível que as palavras-chave possam ser igualadas a termos, o mais correto seria afirmar que existe uma aproximação entre as palavras-chave de um artigo científico e termos de uma linguagem documentária, as quais são planejadas, criadas e controladas especificamente para representação do conteúdo temático dos documentos com vistas a uma posterior recuperação, enquanto as palavras-chave são atribuídas livremente pelo autor.

\subsection{Linguagens Documentárias}

As linguagens documentárias (LD) estão intimamente ligadas à comunicação da informação e, metaforicamente, podem ser consideradas como a ponte entre a informação e o usuário que a necessita. Cintra (2002) afirma que a construção dessas linguagens visa às atividades de indexação, armazenamento e recuperação da informação. Ou seja, nada mais são que símbolos criados e controlados de forma rígida com o intuito de traduzir os conteúdos dos documentos. A partir dessa ideia de criação e controle surge o aspecto da artificialidade, presente em todas as LDs. Através de uma organização baseada na relação de dependência, as LDs constituem sistemas rigorosos, baseados em relações lógicas, ontológicas e hierárquicas. Mas o principal aspecto que leva essas linguagens a adquirirem a característica da artificialidade é o fato do estabelecimento de convenções na construção do sistema, as quais visam à consistência dos termos empregados, proporcionando, assim, uma uniformidade na atividade de indexação e extinguindo, por completo, a ambiguidade tanto na escrita dos termos quanto nos conceitos que esses irão representar no sistema. É importante ressaltar que esse aspecto está presente apenas no controle de termos que irão constituir as LDs, ou seja, na definição do conceito que cada termo irá carregar consigo e, sendo assim, o que cada

1 SAGER (1980) apud GALVÃO, M. C. B. A linguagem de especialidades o texto técnico- científico: notas conceituais. Transinformação, Campinas, v. 16, n. 3, p. 241-251, set/dez. 2004. 
um irá representar dentro do sistema. Mas isso não as torna totalmente imutáveis.

[...] a utilização de unidades retiradas da LN, dá às LDs um caráter particular que as torna, de certa forma, diferentes dos sistemas estáticos. Na sua utilização há como que uma contaminação da mobilidade da LN, passada via escolhas lexicais que se transformam em unidades documentárias. Assim, as LDs não se livram completamente de interferências culturais que acabam por exigir um trabalho quase permanente de atualização (CINTRA, 2002, p. 15).

Fujita (2004a) acredita que as linguagens documentárias são um conjunto controlado de termos que visam à representação de conceitos significativos de assuntos dos documentos utilizados na fase de indexação e busca. Ou seja, na entrada e saída de dados de um determinado sistema de informação. Campos (2001) apresenta uma ideia mais genérica a respeito das LDs, definindo-as como instrumentos utilizados para representar o conhecimento de uma determinada área do saber. Não existe dúvida de que a representação do conhecimento proporcionada pelas LDs é fundamental, mas outro aspecto importante presente nessas linguagens é a convergência proporcionada por elas entre a linguagem do indexador e a linguagem do usuário de um sistema de informação. "Já que vários autores podem utilizar diferentes palavras para expressar uma mesma idéia, assim como os usuários podem apresentar diversidade de vocabulário quando da expressão de uma estratégia de busca" (FUJITA, 2004a).

O uso de diferentes palavras para representar a mesma ideia é um fato comum em todas as áreas do conhecimento. A linguagem dos especialistas, juntamente com o avanço da ciência, sofre modificações em maior ou menor velocidade, dependendo da área do conhecimento. Esse processo natural de modificação da linguagem decorrente da evolução do conhecimento cria, nos sistemas de recuperação da informação, uma capacidade limitada, até certo ponto, de representação da informação, resolvido apenas com o monitoramento dos discursos dos especialistas, de tal modo que possam ser efetuadas constantes atualizações. Para isso, Araujo (2006) afirma que as LDs precisam permitir a incorporação de novos descritores/termos juntamente com suas relações. É preciso estar atento, não somente ao fato de acréscimos de descritores/termos, mas, também, à exclusão desses, que, devido ao processo natural de evolução científica, linguística e terminológica perdem o status de termo, tornandose obsoletos, por não terem a capacidade de representar os novos conceitos decorrentes do avanço da ciência.

Ao se construir LDs, precisa-se ter em mente que elas devam funcionar como um instrumento de organização e comunicação da informação. Portanto, devem permitir que o usuário, através delas, encontre a informação que precisa. Sendo assim, o que se espera dessas 
linguagens é uma operacionalidade que integre o usuário e o sistema de informação dentro de um contexto informacional constituído por demandas informacionais de uma determinada área do conhecimento. Lara (2004) evidencia essas afirmações ao dizer que a linguagem documentária precisa funcionar como código inteligível (dotado de sentido), caracterizar-se como metalinguagem e incorporar o usuário como parte integrante do processo, no qual os códigos remetem a significados particulares e precisos, e a linguagem faz referência a termos e significados compartilhados entre aquela comunidade de usuários. Mais especificamente, "[...] operam no quadro das representações documentárias, vistas como linguagens de comunicação entre a informação documentária e o usuário que dela necessita." (DODEBEI, 2002, p. 56). Para tal, as LDs atuam na atividade de indexação, de modo que buscam uma padronização nessa atividade que visa à representação dos documentos sobre os aspectos de conteúdo.

[...] o grande desafio está sempre na apreensão e divulgação da informação especializada no sentido de que os conteúdos dos documentos sejam identificados e adequadamente registrados por meio do processo de indexação, cuja qualificação maior é dar representatividade aos conceitos veiculados na documentação atualizada. Esse processo de acordo com a área é feito com a ajuda de um vocabulário limitado e controlado, unívoco e coerente, que dá sustentação à linguagem documentária (KRIEGUER, 2004, p. 60).

Com a padronização dos instrumentos e procedimentos que visam uma uniformidade na atividade de indexação, as LDs têm o desafio de atuar nas Unidades de Informação como uma ferramenta de representação temática dos documentos que integram essas unidades, com o objetivo de proporcionar a recuperação, localização e acesso à informação pelo usuário.

\subsection{Terminologia}

O surgimento da Terminologia está diretamente relacionado com 0 desenvolvimento de diversas áreas da ciência no século XVIII e XX. Com a produção intelectual em franca expansão nesse período, verificou-se um aumento vertiginoso no número de documentos a serem inseridos $e$ recuperados nas bibliotecas de todo mundo. O avanço da ciência a passos largos trouxe consigo o aparecimento de novos conceitos e a necessidade de comunicação desses novos conhecimentos entre os especialistas de diversos ramos. Merton ${ }^{2}$ (1973) apud Moraes (2007) afirma que a ciência tem como meta principal a produção de novos conhecimentos e a divulgação de seus resultados. A busca por novos conhecimentos está sempre baseada em conhecimentos anteriores, sendo assim, é essencial que se criem condições para que a comunicação científica entre os

2 MERTON (1973) apud MORAES, A. F. de. Terminologia como indicador qualitativo. Transinformação, Campinas, v. 19, n. $131-38$, jan./abr. 2007. 
especialistas de uma determinada área do conhecimento aconteça o mais naturalmente possível.

A Terminologia surge com uma proposta de normalização e padronização da representação do conhecimento, tornando a comunicação viável entre os especialistas e demais membros da sociedade.

Nessa perspectiva, o processo de normalização e padronização dos termos propostos pela Terminologia Clássica, em princípio, propiciaria uma comunicação mais viável entre os especialistas, uma vez que utilizariam o mesmo signo lingüístico para suas descobertas e idéias em determinada área do conhecimento, além de uma considerável melhora nas comunicações comerciais (VAN DER LAAN, 2002, p. 46).

Duas escolas teóricas dominam o estudo da Terminologia: a Teoria Geral da Terminologia (TGT), de Eugen Wüster, e a Teoria Comunicativa da Terminologia (TCT), de Maria Tereza Cabré e colaboradores.

\subsection{Teoria Geral da Terminologia}

Desenvolvida por Eugen Wüster, a TGT busca estabelecer princípios teóricos que propiciem uma correspondência exata entre os termos e conceitos, dentro dos diversos campos da Ciência e Tecnologia. Seus princípios norteadores são conhecidos como princípio da univocidade (um conceito é designado por um único termo) e da monorreferencialidade (um termo faz referência a um único conceito).

A TGT busca, assim, a objetividade, e seu principal mérito é o entendimento de que a linguagem natural é completamente inadequada para ser empregada no campo da ciência. "[...] com base na filosofia analítica, que considera a linguagem comum inadequada a linguagem científica e acredita numa padronização do conhecimento científico, via uma linguagem universal" (MORAES, 2007, p. 34). Nessa perspectiva, o termo é uma unidade de comunicação que representa o conceito, seu significado é denotativo, composto por palavras determinadas por especialistas de uma área específica do conhecimento. Dessa forma, busca-se uma correspondência exata entre os conceitos e os termos (CAMPOS, 2001), preocupando-se com a determinação do conceito e não com a rotulagem do mesmo, desconsiderando-se, com isso, aspectos importantes da linguagem.

$\mathrm{Na}$ TGT, o conhecimento do assunto (isto é, dos conceitos de determinada área) é elemento norteador para a criação do termo. Wüster embasa toda sua metodologia na análise do conceito, que é estável, e desconsidera o termo devido à sua instabilidade advinda do papel de comunicador do conhecimento: o conceito é universal e permanece imutável através dos tempos. A ideia de que os termos relacionam-se a conceitos e não a significados, que são, por natureza, passíveis de 
variação conforme o contexto discursivo e por ação do falante especializado, caracteriza a visão de Wüster, para quem a fixação do termo se dá via normalização e não por ativação do discurso do especialista. Segundo os preceitos da TGT:

[...] os termos são vistos como elementos naturais de línguas naturais, pois são compreendidos como unidades de conhecimento que comportam denominações... isso evidencia uma valorização da dimensão conceitual das terminologias em detrimento do ponto de vista que as considera como elementos naturais dos sistemas lingüísticos... (KRIEGER; FINATTO 2004, p. 33).

Com essa visão, o conceito é o ponto central de toda essa escola, relegando-se o termo a um segundo plano comprometendo a dinâmica da linguagem. Krieger e Finatto (2004, p. 214) afirmam que:

[...] os limites de alcance da TGT expressam o apagamento dos aspectos comunicativos e pragmáticos, inerentes ao léxico das linguagens especializadas. Caracteriza-se desse modo, um forte reducionismo do funcionamento da linguagem, aspecto que, inclusive, se tornou um dos focos principais das críticas à TGT.

\subsection{Teoria Comunicativa da Terminologia}

Contrapondo-se à TGT de Wüster, surge, no final do século $X X$, a TCT, criada por Maria Tereza Cabré e colaboradores. Com bases teóricas e perspectivas diferentes da TGT, essa escola não tem o objetivo de negar a importância das teorias de Wüster, mas, sim, dar uma resposta a algumas das suas falhas teóricas e metodológicas. Na perspectivada TCT, os termos passam a ser considerados e tratados como unidades linguísticas e instrumentos de comunicação. Segundo Cabré (2005), as bases da TCT são:

- assumir as unidades terminológicas como objeto central de estudo da Terminologia;

- entender as unidades terminológicas como "poliédricas" (linguísticas, cognitivas e sociocomunicativas), passíveis, portanto, de existirem na linguística, na ciência cognitiva e na comunicação social, embora cada área possua suas próprias teorias;

- a análise das unidades terminológicas se dá através dos textos e da oralidade;

- aceitar a polissemia e sinonímia; 
- as unidades terminológicas dividem com outras unidades linguísticas (morfológicas, sintagmáticas e sintáticas), a expressão do conhecimento especializado; e

- é o discurso especializado que "ativa" o valor da unidade terminológica.

É notório que a TCT é uma teoria muito mais completa, na medida em que analisa o discurso do especialista inserido em um contexto linguístico, respeitando as variações decorrentes da geografia, de tempo, de léxico, de fonemas e de grafia, não ignorando, assim, os fatores de evolução da língua. Seguindo esses preceitos, os termos não podem ser considerados como unidades autônomas.

Essas entidades são potencialmente termos quando usadas em determinados contextos, isto é, como termos elas podem ter duas atuações: representar e transferir o conhecimento especializado dentro de uma representação textual e discursiva (MORAES, 2007, p. 34).

O termo constitui-se em uma criação lexical do falante especializado, que não apenas denomina de formas diferentes um mesmo conceito, como, também, dá outros significados. Portanto, a variação terminológica pode ocorrer na medida em que um conceito pode ter várias representações. Na realidade linguística, a padronização dos termos sugerida por Wüster e o princípio de univocidade, caracterizado pela monorreferencialidade, não importam para o falante, que na sua prática discursiva opta, muitas vezes, pelo uso de sinônimos e variantes.

\section{Conclusões}

A palavra-chave, sob o ponto de vista dos sistemas de recuperação de informação (SRI), deve ter sua importância reconhecida, na medida em que pode ser empregada pelos usuários como expressão de busca, uma vez que é rótulo de conceitos expressos pelos autores. A relação que se estabelece entre SRI e o usuário é de comunicação. Isto significa que o código empregado na busca de informação deve ser decodificado pelo sistema, que responderá relacionando itens de seu acervo compatíveis com as necessidades informacionais ou não. Para que este processo comunicativo ocorra, é necessário que o processo de representação da informação seja realizado empregando-se uma linguagem documentária que represente o acervo linguístico do usuário.

Entendendo que artigos de periódicos científicos, teses e dissertações são materiais que seguem um rigor metodológico em sua constituição, a forma mais adequada e segura de se estabelecer a correlação entre usuário e SRI, que contenha documentos de natureza científica, é no momento em que o autor realiza a análise de assunto, combina a exploração da estrutura textual e utiliza uma sistemática de identificação de conceitos. Os autores têm plenas condições de realizar 
uma análise de assunto identificando conceitos importantes e relevantes. O problema pode ocorrer na tradução e transformação desses conceitos em palavras-chave capazes de possuir valor semântico, representando corretamente os assuntos e, consequentemente, tornando-os passíveis de uma recuperação da informação após o emprego dessas, como estratégias de busca por parte dos usuários. O ideal seria que esse processo fosse realizado em colaboração com o bibliotecário. O trabalho realizado, de forma colaborativa, entre autor e bibliotecário possibilitaria que as palavras-chave fossem determinadas de forma mais precisa.

Uma alternativa viável e prática para a resolução desse problema linguístico seria a criação de uma norma que tratasse exclusivamente das palavras-chave. Tanto a norma ABNT 12.676 - Métodos para análises de documentos - Determinação de seus assuntos e seleção de termos de indexação, quanto à norma ABNT 6028 - Informação e documentação Resumo - Apresentação, trazem, em seu bojo, questões importantes no que diz respeito à análise de assuntos e apresentação gráfica das palavras-chave. Seria muito importante que essas questões fizessem parte de uma mesma norma, propiciando aos autores um acesso facilitado e uma maior praticidade na consulta. Atenta-se para o fato dessas normas não tratarem de aspectos linguísticos importantes, como o uso de qualificadores, abreviaturas, pessoas, localizações geográficas e uso de sintagmas longos como palavras-chave. Tal evidência torna necessária a criação de uma norma que aborde as questões linguísticas já mencionadas, de forma a facilitar, por parte dos autores, a atribuição correta de palavras-chave, possibilitando uma recuperação da informação com grau satisfatório de pertinência.

As conclusões e sugestões desse trabalho têm como pressuposto que as palavras-chave são elementos de representação de informações e podem ser empregadas como estratégias de buscas dessas informações.

\section{Referências}

ARAUJO, V. M. A. P. de. Documentação, terminologia e lingüística: uma interface produtiva. 2006. 165 f. Dissertação (Mestrado em Letras) Universidade Federal do Rio Grande do Sul, Instituto de Letras, Programa de Pós-Graduação em Letras, Porto Alegre, 2006.

CABRÉ, M. T. La terminologia, uma disciplina en evolución: passado, presente y algunos elementos de futuro. Revista Debate Terminológico, [Paris?], n. 1, abr. 2005. Disponível em: < http://www.riterm.net/revista/ n 1/cabre.pdf $>$. Acesso em: 4 out. 2008.

CAMPOS, M. L. de A. Linguagem documentária: teorias que fundamentam sua elaboração. Niterói: EDUFF, 2001. 133 p.

CINTRA, A. M. M. (Org.). Para entender as linguagens documentárias. 2. ed. São Paulo: Polis, 2002.

DODEBEI, V. L. D. Tesauro: linguagem de representação da memória documentária. Niterói: Intertexto, 2002. 
FUJITA M. S. L. A leitura Documentária na Perspectiva de suas Variáveis: leitor-texto-contexto. DataGramaZero: Revista de Ciência da Informação, Rio de Janeiro, v. 5, n. 4, ago. 2004a. Disponível em: <http://www.dgz.org.br/ago04/F I art.htm>. Acesso em: 2 set. 2008.

FUJITA, M. S. L. A Representação documentária de artigos científicos em educação especial: orientação aos autores para determinação de palavraschaves. Rev. Bras. Ed., Marília, v. 10, n. 1, p. 257-272, set./dez. 2004b.

GALVÃO, M. C. B. A Linguagem de especialidade e o texto técnicocientífico: notas conceituais. Transinformação, Campinas, v. 16, n. 3, p. 241-251, set./dez. 2004.

KRIEGER, M. da G.; FINATTO, M. J. B. Introdução à terminologia: teoria e prática. São Paulo: Contexto, 2004.

LARA, M. L. G. Linguagem documentária e terminologia. Transinformação, Campinas, v. 16, n. 3, p. 231-240, set./dez. 2004.

MORAES, A. F. de. Terminologia como indicador qualitativo. Transinformação, Campinas, v. 19, n. 1, 31-38, jan./abr. 2007.

ORLANDI, E. P. O que é lingüística. São Paulo: Brasiliense, 2007.

SAUSSURE, F. de. Curso de lingüística geral. São Paulo: Cultrix, 2006. $279 \mathrm{p}$.

VAN DER LAAN, R. H. Tesauro e terminologia: uma inter-relação lógica. 2002. 262 f. Tese (Doutorado em Letras) - Universidade Federal do Rio Grande do Sul, Instituto de Letras, Programa de Pós-Graduação em Letras, Porto Alegre, 2002. 